\title{
Part-time doctors - reducing hours to reduce burnout
}

Cite as: CMAJ 2018 September 4;190:E1055-6. doi: 10.1503/cmaj.109-5621

Posted on cmajnews.com on Aug. 15, 2018.

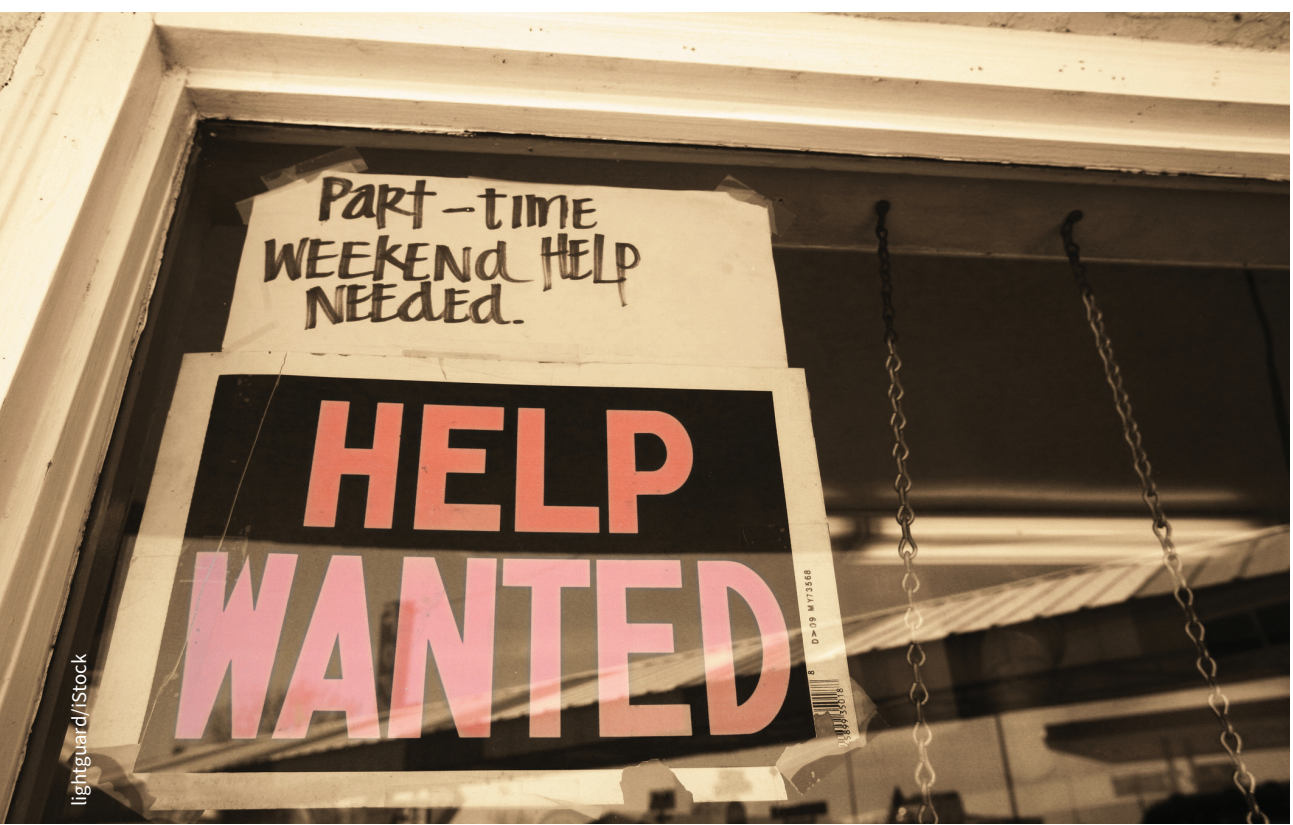

Part-time work is common in many industries, but not in medicine.

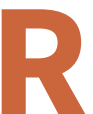
educing working hours can help recovery from burnout, but many doctors are finding that cutting back is challenging and sometimes not an option.

Dr. Jeremy Topin, a pulmonary and critical-care physician in Chicago, Illinois, has been working part-time for a year. "I was making twice as much [working full time], but I'm twice as happy now," he says. He had been the sole income earner for his family, but his wife started tutoring and they saved aggressively in the years before his transition to part-time.

Topin realized he was burned out when he got anonymous feedback that residents didn't want to work with him. Earlier in his career, he'd gotten glowing reviews. "I always prided myself on figuring out how to connect, how to adapt to the patient or the student," he says. "I stopped doing that. I got frustrated much quicker."

Since going part-time, he has time to write, coach water polo, and spend more time with his teenage children. At work, he now approaches a challenge with an attitude of how he can help instead of dismissing it as "someone else's problem," says Tobin. To appease his colleagues, he takes full weekend call hectic, 12-hour days - but works only 23 weeks of the year. But he wrestled with questions like, "Why could I not hack it?" He also wondered, with respect to his colleagues, "Why has it not become too much for them?"
Surveys show more Canadian physicians are experiencing burnout. In the 2017 workforce survey of the Canadian Medical Association, 29\% said they planned to reduce working hours in the coming two years; only $7 \%$ planned to increase hours. A 2017 survey of US doctors found $20 \%$ planned to reduce clinical hours in the following year.

Dr. Andrew Clarke, executive director of the Physician Health Program of Doctors $B C$, says his organization provides resources for burned-out doctors on how to scale back. "Generally, when physicians recover from burnout, it usually involves reducing their total working hours," he says. The time is needed to rejuvenate physically and emotionally, and "to implement some kind of recovery and coping strategy." That often involves figuring out ways to do more of the work that is enjoyable and less of the work that is draining.

According to Clarke, cutting hours can be "the hardest in family practice." Because the need is so great, family physicians feel guilty about abandoning patients or increasing the workload of their peers. "You basically end up having to discharge patients from your practice," he says. "It's going to be unpopular."

Some doctors find that working part time isn't a solution, however. "Oftentimes it doesn't work," says Dr. Frank Warsh, a former family doctor and author of The Flame-Boiled Doctor: From Boyhood to Burnout in Medicine. Before leaving family medicine, Warsh tried working part-time, but "it increases the stress on your off days. The paperwork never stops." Warsh found that the mental health and addiction-related crises of 
his patients often meant visiting or calling patients on his days off.

He left his job at a community health centre in 2015 after realizing, "I'm either going to walk away from this or l'm going to become an alcoholic." At the time, he would drink to wind down from the high-stress days. He now takes on a couple of cases a week as a coroner.

One Canadian rural general surgeon, who requested anonymity, is working about a shift a week at another hospital while on leave from a group practice to recover from burnout. The surgeon, a single mother of two children, believes that cutting her workload by a fifth would have provided enough time to relieve stress and be more available for her family. But a proposal to share her workload with a new doctor was rejected by colleagues who didn't want to bring in competition for referrals.

"Physicians do not understand burnout; this is something that's seen as a defect in the individual and not a systemic issue," said the surgeon.

In Topin's case, reducing hours has allowed him to once again find joy and fulfillment in his days. "Sometimes, the things that keep you going and sustain you can be few and far between," he says. "But I love medicine. I love seeing patients. I would lament walking away completely."

Wendy Glauser, Toronto, Ont. 